\title{
Effect of early stress on hippocampal gray matter is influenced by a functional polymorphism in EAAT2 in bipolar disorder
}

\author{
Sara Poletti *, Clara Locatelli, Daniele Radaelli, Cristina Lorenzi, Enrico Smeraldi, \\ Cristina Colombo, Francesco Benedetti
}

Department of Clinical Neurosciences, Scientific Institute and University Vita-Salute San Raffaele, Milan, Italy

\section{A R T I C L E I N F O}

\section{Article history:}

Received 4 December 2013

Received in revised form 17 January 2014

Accepted 30 January 2014

Available online 8 February 2014

\section{Keywords:}

Adverse childhood experiences

Bipolar disorder

EAAT2

Glutamate

Hippocampus

\begin{abstract}
A B S T R A C T
Current views on the pathogenesis of psychiatric disorders focus on the interplay between genetic and environmental factors, with individual variation in vulnerability and resilience to hazards being part of the multifactorial development of illness. The aim of the study is to investigate the effect of glutamate transporter polymorphism SLC1A2-181A > C and exposure to Adverse Childhood Experiences (ACE) on hippocampal gray matter volume of patients with bipolar disorder (BD).

Patients exposed to higher levels of ACE reported lower gray matter volume. The effect of SLC1A2-181A $>$ C revealed itself only among patients exposed to lower levels of ACE, with T/T homozygotes showing the lowest, and $\mathrm{G} / \mathrm{G}$ the highest, gray matter volume.

The greatest difference between high and low exposures to ACE was observed in carriers of the G allele. Since the mutant $G$ allele has been associated with a reduced transcriptional activity and expression of the transporter protein, we could hypothesize that after exposure to highest levels of ACE G/G homozygotes are more vulnerable to stress reporting the highest brain damage as a consequence of an excess of free glutamate.
\end{abstract}

(c) 2014 Elsevier Inc. All rights reserved.

\section{Introduction}

Current views on the pathogenesis of psychiatric disorders focus on the interplay between genetic and environmental factors, with individual variation in vulnerability and resilience to hazards being part of the multifactorial development of illness (Wermter et al., 2010). An association between genetic and environmental liabilities for schizophrenia and bipolar disorder (BD), and cortical thickness, has been reported (Hulshoff Pol et al., 2012) together with an interactive effect on brain volume between genetic liability for schizophrenia and both obstetric complications and cannabis use (Geoffroy et al., 2013). Among environmentally mediated causal risk processes adverse childhood experiences (ACE) have been shown to influence both physical and mental health

\footnotetext{
Abbreviations: BD, Bipolar Disorder; ACE, Adverse Childhood Experiences; GM, Gray Matter; Glx, glutamate/glutamine; NMDA, N-methyl-D-aspartate; EAATs, excitatory amino acid transporters; SLC1A2, solute carrier family 1 (glial high affinity glutamate transporter), member; 2DSM-IV, Diagnostic and Statistical Manual of Mental Disorders; SCID, Structured Clinical Interview for DSM-IV Axis I Disorders; RFQ Risky Family Questionnaire; GLM, general Linear Model; ANOVA, analysis of variance; NAA, N-acetyl aspartate.

* Corresponding author at: Istituto Scientifico Ospedale San Raffaele, Department of Clinical Neurosciences, San Raffaele Turro, Via Stamira d'Ancona 20, Milano, Italy. Tel.: +3902 26433156; fax: + 390226433265 .

E-mail address: poletti.sara@hsr.it (S. Poletti).
}

(Felitti et al., 1998) and in patients with BD have been reported to affect both the onset and course of illness (Johnson and Roberts, 1995). Exposure to physical, sexual, and emotional abuse in childhood is associated with earlier onset of BD, rapid cycling (Brodsky et al., 2001; Swann et al., 2005), an increased likelihood of self-injurious behavior (Newport et al., 2002), and higher severity and number of suicide attempts (Brodsky et al., 2001; Gladstone et al., 1999; Swann et al., 2005). Moreover also exposure to certain types of parenting practices or to maltreatment during childhood increases individuals' vulnerability to mood disorders (Alloy et al., 2006) possibly altering permanently the stress response system, sensitizing individuals to later stress, and leading to early onset and severe course of the disorder (Post et al., 2001).

Recent brain imaging studies confirmed the possibility to explore in adult life the persistent neural correlates of adverse childhood experiences (ACE). Among healthy humans, the offspring of families marked by harsh parenting with overt family conflict and deficient nurturing ("risky families", RF) had higher activation of prefrontal cortex and reduced activation of limbic structures in response to an emotional task (Taylor et al., 2006). Our group confirmed the functional and structural effects of these ACE on cortico-limbic structures of both healthy and schizophrenic subjects, as well as in the caudate head of obsessive compulsive patients (Benedetti et al., 2012), and showed that differences in neural responses are paralleled by differences of gray matter (GM) volumes (Benedetti et al., 2011). 
The hippocampal formation is a particularly plastic and vulnerable brain region, and as a consequence it is one of the structures more sensitive to stress (McEwen, 2007), including childhood abuse (Andersen et al., 2008). Studies focusing on the consequences of maltreatment and abuse during childhood found diminished hippocampal volume in adults with maltreatment histories (Bremner et al., 1997; Frodl et al., 2010; Weniger et al., 2009). Alterations in hippocampal volume have been reported in a multitude of psychiatric disorders, including major depression, post traumatic stress disorder, borderline personality disorder, schizophrenia and BD (Geuze et al., 2005).

Hippocampal volume decrease is also associated with illness burden in BD patients not taking lithium (Hajek et al., 2006; McKinnon et al., 2009; Moorhead et al., 2007) while lithium has been shown to increase hippocampal volume in both prospective (Yucel et al., 2008) and retrospective studies (Bearden et al., 2008; Yucel et al., 2008).

Converging lines of evidence from animal studies suggest that acute exposure to stress rapidly increases glutamate release in hippocampus (Popoli et al., 2012). Glutamate is the principal excitatory neurotransmitter in the central nervous system with glutamatergic neurons being prominently represented in the cerebral cortex and limbic regions of the brain. Evidence suggests that alterations in glutamatergic systems may contribute to the pathophysiology of depression (Krystal et al., 2002).

High levels of glutamate in the brain have been associated both to neurotrophic and toxic effect. Accumulation of excess extracellular glutamate and subsequent overstimulation of glutamatergic receptors increase the production of reactive and excitotoxic oxygen/nitrogen species, which induce oxidative stress leading to neuronal death (Kim et al., 2011). Glutamate signaling is also involved in brain development and synaptic plasticity, both of which are modified in individuals affected by $\mathrm{BD}$, and have been implicated in the etiology of the disorder (Manji et al., 2003). An elevated brain glutamate/glutamine (Glx) ratio and reduced levels of N-methyl-D-aspartate (NMDA) receptor subunits are reported in postmortem brain from BD patients (Hashimoto et al., 2007). Several single proton magnetic resonance spectroscopy studies found Glx to be consistently elevated both in adult (Cecil et al., 2002; Dager et al., 2004) and pediatric (Castillo et al., 2000) patients affected by BD and in a previous study we found that changes in the Glx/creatine ratio in bipolar depressed patients parallel antidepressant response (Benedetti et al., 2009). Riluzole, which inhibits glutamate release, was shown to be able to promote antidepressant response in bipolar resistant depressed patients (Singh et al., 2004; Zarate et al., 2005). The NMDA receptor antagonist Ketamine can, in vitro, increase glutamatergic neuron firing rate and presynaptic glutamate release (Moghaddam et al., 1997), and showed robust and rapid antidepressant effects (Machado-Vieira et al., 2009).

The inactivation of glutamate is handled by a series of molecular glutamate transporters (excitatory amino acid transporters - EAATs) which are membrane-bound pumps that closely resemble ion channels. These transporters play the important role of regulating concentrations of glutamate in the extracellular space, maintaining it at low physiological levels that promote biological function without promoting toxicity (Danbolt, 2001). Five human excitatory amino acid transporters have been cloned, and among them, EAAT2 is responsible for up to $95 \%$ of extracellular glutamate clearance (Rothstein et al., 1996). Even if EAAT2 is expressed primarily on astrocytes, it also has been found in neurons and oligodendrocytes (Rao et al., 2012).

The gene encoding EAAT2 in humans is SLC1A2 [solute carrier family 1 (glial high affinity glutamate transporter), member 2], located on chromosome 11p13-12 (Meyer et al., 1997). Mallolas and colleagues (Mallolas et al., 2006) described a T-to-G (DNA forward strand) functional polymorphism at $-181 \mathrm{bp}$ from the transcription start site of the EAAT2 gene which is commonly known as $-181 \mathrm{~A}>\mathrm{C}$. The mutation abolishes a putative regulatory site for activator protein- 2 and creates a new binding site for the transcription repressor factor GC-binding factor 2 , resulting in less transporter expression and with the $\mathrm{C}$ allele inducing a 30\% reduction in promoter activity compared with the A allele. Impaired glutamate uptake by dysfunction or reduced expression of EAAT2 has been implicated in the pathogenesis of various neurodegenerative diseases, such as Alzheimer's disease, Huntington's disease, amyotrophic lateral sclerosis (Kim et al., 2011) and also schizophrenia (Bauer et al., 2010; Ohnuma et al., 1998, 2000; Smith et al., 2001). In BD altered levels of EAAT2 protein and RNA have been found in postmortem prefrontal cortex (Rao et al., 2012). A reduced expression of the membrane transporters SLC1A2 was also reported in major depression while a trend has been observed in bipolar subjects (Medina et al., 2013). It has been suggested that stress can induce changes in glutamate synapses and circuitry. Acute stress has been suggested to increase glutamate uptake in the frontal cortex and hippocampus of rats (Gilad et al., 1990) but later studies have yielded mixed results showing either a glucocorticoid-mediated suppression of glutamate uptake (Yang et al., 2005) or no effect (Fontella et al., 2004). Exposure to chronically elevated levels of glucocorticoids increase EAAT2 protein expression throughout the hippocampus (Autry et al., 2006); and on the upregulation of hippocampal EAAT2 found in aged stressed rats has been interpreted as a neuroprotective response to stress-induced elevations in glutamate in the synaptic cleft (Duan et al., 1999; Liang et al., 2008) or as a response to increased corticosterone levels (Rauen and Wiessner, 2000). Increased astrocytic EAAT2 expression appears to afford greater neuroprotection under excitotoxic conditions (Rosenberg and Aizenman, 1989; Weller et al., 2008). In a rat model of chronic restraint stress, Reagan et al. reported an increased hippocampal EAAT2 expression followed by a downregulation after treatment with the antidepressant tianeptin (Reagan et al., 2004).

In the hippocampus, EAAs and glucocorticoids mediate biphasic effects on structure and function. Acutely low to moderate physiological levels of adrenal steroids and EAAs enhance synaptic function and certain types of memory, whereas higher levels of both mediators have the opposite effect (Joels, 2006). Chronically adrenal steroids and EAAs mediate adaptive plasticity involving spine synapse turnover and dendritic shrinkage (McEwen, 1999).

If changes in glutamate release and turnover contribute to the neurobiological effects of stress on the hippocampus, it can be hypothesized that factors affecting the clearance of glutamate could interact with the degree of stress exposure in mediating this effect. Here we tested this hypothesis by studying the effect of SLC1A2-181A > C (rs4354668) polymorphism and exposure to ACE on hippocampal gray matter volume of patients with BD.

\section{Methods}

\subsection{Patients and data collection}

We studied 86 Caucasian subjects ( 56 females, 30 males) consecutively referred to our university hospital from January 2009 to December 2012 for BD type I (DSM-IV - Diagnostic and Statistical Manual of Mental Disorders, 4th Edition (American Psychiatric Association, 1994)-criteria; SCID - Structured Clinical Interview for DSM-IV Axis I Disorders (First et al., 1996)-interview). Exclusion criteria were other diagnoses on Axis I, mental retardation on Axis II, history of epilepsy and major medical and neurological disorders. None of the patients took lithium in the previous six months.

Handedness was assessed with the Edinburgh inventory (Oldfield, 1971). Severity of ACE was rated on the Risky Families Questionnaire (RFQ) (Taylor et al., 2006) after MRI scanning. The RFQ has been adapted from an instrument originally developed to assess the relation of family stress to mental and physical health outcomes in adulthood (Felitti et al., 1998). The instrument is aimed at rating the degree of harsh parenting with overt family conflict and deficient nurturing experienced by the children in their familial environment. Previous research validated this questionnaire against clinical interviewers; the dual assessment (questionnaire and interview) demonstrated high agreement 
and reliability (Taylor et al., 2004). This approach has been proven successful in detecting the structural and functional brain correlates of ACE in adult life (Benedetti et al., 2011; Taylor et al., 2006). Each group of participants was then divided into two subgroups, using median values as a discriminant between high and low scores of the RFQ.

All data were collected in the same day. The work described has been carried out in accordance with The Code of Ethics of the World Medical Association (Declaration of Helsinki). After complete description of the study to the subjects a written informed consent was obtained. The local ethical committee approved the study protocol.

\subsection{Genotyping}

DNA was extracted from whole blood by a manual extraction, using the "Illustra blood genomic Prep Midi Flow kit" (GE Healthcare, Milan, Italy). To identify the polymorphism EEAT2-181A $>$ C T/G (DNA forward strand), a standard polymerase chain reaction (PCR) was carried with the following primers: $5^{\prime}$-GCC ACC TGT GCT TTG CTG-3' and 5'-TGA TGT CAG CTC TCG ACG AA-3'. The PCR was carried out in a $10 \mu \mathrm{l}$ volume containing 150 ng genomic DNA, $1 \mu$ of $1 \times$ Hot Master Taq Buffer with $\mathrm{Mg}++$ (Eppendorf), $0.1 \mu \mathrm{l}$ of each primer [ $50 \mu \mathrm{M}], 1 \mu \mathrm{l}$ of deaza-dNTPs [10 mM], $0.5 \mu$ of Dimethyl sulfoxide (DMSO) solution (Sigma-Aldrich,

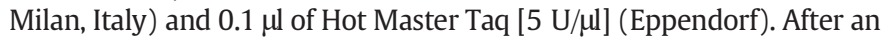
initial step of $5 \mathrm{~min}$ at $94{ }^{\circ} \mathrm{C}, 35$ cycles of amplification $\left(35 \mathrm{~s}\right.$ at $94{ }^{\circ} \mathrm{C}, 35$ s at $58{ }^{\circ} \mathrm{C}, 45 \mathrm{~s}$ at $70{ }^{\circ} \mathrm{C}$ ) and a final extension step of $10 \mathrm{~min}$ at $70{ }^{\circ} \mathrm{C}$ were performed. An aliquot of PCR product was digested using Msp I $(20 \mathrm{U} / \mu \mathrm{l})$ (New England Biolabs, England, UK) and incubated at $37{ }^{\circ} \mathrm{C}$ for $8 \mathrm{~h}$; fragments were separated in agarose gels. Depending on the presence of two or three restriction Msp I sites, either three fragments (allele T) or four fragments (allele $\mathrm{G}$ ) were produced.

\subsection{Brain imaging procedures and data analysis}

Brain imaging volumetric T1-weighted sequences were acquired on a 3.0 T scanner (Gyroscan Intera, Philips, Netherlands) using a 6 channels SENSE head coil using a T-1-weighted MPRAGE sequence (TR $25.00 \mathrm{~ms}$, TE $4.6 \mathrm{~ms}$, yielding 220 transversal slices with a thickness of $0.8 \mathrm{~mm}$ ). Images were computed, overlaid on anatomic images, and analyzed using Statistical Parametric Mapping software (SPM8, Wellcome Department of Imaging Neuroscience, Institute of Neurology and the National Hospital for Neurology and Neurosurgery; London, England) and the voxel-based morphometry (VBM) toolbox (VBM8; http:// $\mathrm{dbm}$.neuro.uni-jena.de/vbm/) implemented in SPM8, which combines tissue segmentation, bias correction, and spatial normalization into a unified model. We used the optimized VBM procedure, which normalizes gray matter (GM) segmented images to a standard space by matching them to their template (Ashburner and Friston, 2005). The procedure yielded modulated GM normalized images: modulated parameters were used to test for voxelwise differences in the relative volume of GM by compensating for the effects of warping, to ensure that the total amount of GM in a region is the same before and after spatial normalization (Good et al., 2001). The voxel size for all images was resliced to $1 \times 1 \times 1 \mathrm{~mm}$. We realigned the scans to correct for head movement. Images were then normalized to the standard EPI template volume of the Montreal Neurological Institute (MNI) reference brain, and smoothed using a 8-mm full-width at half-maximum (FWHM) isotropic Gaussian kernel.

Data were analyzed within the context of the General Linear Model (GLM). Modulated images were entered into a second level analysis of variance (ANOVA) with genotype and ACE (high and low) as factors. This procedure allowed for the regions where both factors significantly influenced brain volume (conjunction analysis, as implemented in the SPM8 statistical software package) to be investigated, and to test the levels of significance of the main effects of EAAT2 and of ACE one by one. We included as covariates age, sex, duration of illness, number of episodes and handedness as possible confounding factors. Statistical threshold was $\mathrm{P}<0.05$ corrected for multiple comparisons with whole-brain family-wise error (FWE) correction.

Using the Wake Forest PickAtlas software (Wake Forest University, USA; www.fmri.wfubmc.edu), statistical maps were limited to the hippocampus.

\section{Results}

Allelic frequencies were similar to those observed for the general population ( $\mathrm{T}=58.7 \%$; $\mathrm{G}=41.3 \%$ ) (Mallolas et al., 2006). The distribution of EAAT2 genotypes ( $\mathrm{T} / \mathrm{T} \mathrm{n}=29, \mathrm{~T} / \mathrm{G} \mathrm{n}=43, \mathrm{G} / \mathrm{G} \mathrm{n}=14$ ) respected the Hardy-Weinberg equilibrium $\left(\chi^{2}=0.085, \mathrm{p}=0.77\right)$. Clinical and demographical data are shown in Tables 1 and 2. No difference between high ACE and low ACE reached significance (Table 1) or among genotypic groups (Table 2).

At the VBM analysis the combined effects of genotype and ACE (conjunction analysis) survived the statistical threshold in two main clusters in the right hippocampus (MNI coordinates 27-42 $1 ; \mathrm{F}=8.73, \mathrm{Z}=$ 4.14, $\mathrm{p}-\mathrm{FWE}=0.002 ; 34-28-14 ; \mathrm{F}=6.70, \mathrm{Z}=3.65, \mathrm{p}-\mathrm{FWE}=$ 0.015 ) and one in left hippocampus (at MNI coordinates $-33-15$ $-21 ; \mathrm{F}=19.14, \mathrm{Z}=5.93$, $\mathrm{p}-\mathrm{FWE}<0.001$ ) (Figs. 1 and 2 ).

In these clusters patients with exposure to higher levels of ACE had lower gray matter volume, a main effect that remained significant when considered alone (at MNI coordinates $-33-15-21 ; \mathrm{T}=3.53$, $\mathrm{Z}=3.38$, p FWE $=0.016$ ) (Fig. 3).

The effect of SLC1A2-181A > C revealed itself only among patients exposed to lower levels of ACE, among whose T/T homozygotes showed the lowest, and G/G the highest, gray matter volume in two main clusters in the right hippocampus (MNI coordinates $30-33-9$; $\mathrm{T}=$ 16.84, $\mathrm{Z}>8.2$, p-FWE $<0.001 ; 34-25-14$; $\mathrm{T}=16.29, \mathrm{Z}>8.2$, p-FWE $<0.001$ ) and one in left hippocampus (at MNI coordinates $-30-13-14$; $\mathrm{T}=21.59, \mathrm{Z}>8.2$, p-FWE < 0.001) (Fig. 2 right). Among patients exposed to high ACE all genotypes showed similar lower gray matter volumes. Adding lifetime history of lithium treatment (months of treatment) as covariate in the analysis didn't changed the observed data.

\section{Discussion}

This is the first study to investigate the role of SLC1A2-181A > C genotype and ACE in influencing hippocampal volume in patients affected by BD. The main result is a joint effect of both ACE and SLC1A2-181A $>C$ on hippocampal volume. SLC1A2-181A > C functional polymorphism was shown to significantly influence gray matter volume in subjects with low ACE, with wild type T homozygote presenting the lowest volume, $G$ homozygote reporting the highest volume and heterozygotes showing an intermediate phenotype. Independent of this effect higher ACE associated with a reduced hippocampal volume.

The greatest differences between high and low exposure to ACE was observed in $\mathrm{G} / \mathrm{G}$ homozygotes which reported significantly higher gray matter volume when exposed to less stress.

Table 1

Clinical and demographic characteristics of the sample divided according to adverse childhood experiences.

\begin{tabular}{|c|c|c|c|}
\hline & \multicolumn{2}{|c|}{ Adverse childhood experiences } & \multirow[b]{3}{*}{$\mathrm{p}$} \\
\hline & High $\mathrm{n}=43$ & Low $n=43$ & \\
\hline & Mean \pm SD & Mean \pm SD & \\
\hline Age & $44.18 \pm 11.76$ & $46.69 \pm 11.82$ & 0.33 \\
\hline Onset & $28.25 \pm 8.79$ & $32.21 \pm 10.51$ & 0.06 \\
\hline Education & $11.73 \pm 4.29$ & $11.45 \pm 4.41$ & 0.77 \\
\hline Duration of illness & $15.93 \pm 10.61$ & $14.49 \pm 10.15$ & 0.52 \\
\hline Number of episodes & $10.86 \pm 16.96$ & $8.28 \pm 10.32$ & 0.39 \\
\hline Handedness & $20.84 \pm 6.64$ & $20.26 \pm 6.91$ & 0.69 \\
\hline
\end{tabular}


Table 2

Clinical and demographic characteristics of the sample as a whole and divided according to SLA1A2-181A > C genotype.

\begin{tabular}{|c|c|c|c|c|c|}
\hline & Total Sample & $\mathrm{GG}(\mathrm{n}=14)$ & EAAT2 GT $(n=43)$ & $\mathrm{TT}(\mathrm{n}=29)$ & \\
\hline & Mean \pm SD & Mean \pm SD & Mean \pm SD & Mean \pm SD & $\mathrm{p}$ \\
\hline Age & $45.44 \pm 11.78$ & $46.43 \pm 12.78$ & $45.37 \pm 11.07$ & $45.07 \pm 12.69$ & 0.94 \\
\hline Onset & $30.23 \pm 9.83$ & $31 \pm 7.78$ & $30.69 \pm 9.50$ & $29.17 \pm 11.32$ & 0.77 \\
\hline Education & $11.96 \pm 2.97$ & $11.61 \pm 3.47$ & $12.33 \pm 2.22$ & $11.84 \pm 3.34$ & 0.55 \\
\hline Duration of illness & $15.21 \pm 10.35$ & $15.43 \pm 11.49$ & $14.67 \pm 10.47$ & $15.89 \pm 9.92$ & 0.88 \\
\hline Number of episodes & $9.57 \pm 14.02$ & $10.43 \pm 12.55$ & $9.88 \pm 17.36$ & $8.69 \pm 8.36$ & 0.91 \\
\hline $\mathrm{ACE}$ & $26.64 \pm 10.19$ & $27.28 \pm 10.56$ & $25.28 \pm 9.97$ & $28.34 \pm 10.43$ & 0.45 \\
\hline Handedness & $20.55 \pm 6.74$ & $20.71 \pm 7.28$ & $21.16 \pm 5.25$ & $19.55 \pm 8.39$ & 0.61 \\
\hline
\end{tabular}

Since the mutant $\mathrm{G}$ allele has been associated with a reduced transcriptional activity and expression of the transporter protein, this effect could be due to an increase in glutamate levels.

A sparse but consistent literature associated BD and its most detrimental clinical features with a reduced glutamate import to brain structures. Indeed an increase of glutamate levels in the dorsolateral prefrontal cortex in major depression has been reported following clinical improvement (Luborzewski et al., 2007). In bipolar patients, lithium increases the activity of glutamine synthetase (Marcus et al., 1986), which is abnormally low in the brain of suicide victims (Klempan et al., 2009) thus possibly leading to prolonged alterations in glutamate and GABA function (Kalkman, 2011).

Higher levels of hippocampal glutamate have been positively associated with hippocampal N-acetyl aspartate (NAA) levels in bipolar I patients in stable remission on long-term lithium prophylaxis, and both inversely correlated with diurnal cortisol levels (Colla et al., 2009). In the hippocampus, disruptions in neuronal integrity have been marked by altered NAA/Cr levels in several studies of BD compared to healthy controls (Atmaca et al., 2006; Bertolino et al., 2003; Blasi et al., 2004) and increased levels of NAA in the brain have been found to be induced by lithium administration, thus paralleling clinical amelioration (Moore et al., 2000). Following a recent hypothesis NAA serves as a reservoir for glutamate and can be converted into glutamate when necessary (Clark et al., 2006). If increased NAA levels are positively associated with neurotrophic effect and also with glutamate levels, we could surmise that $G$ carriers show greater gray matter volume in the hippocampus reflecting a neurotrophic effect of glutamate. Indeed while excess of glutamate levels is associated to excitotoxicity, low physiological levels promote synaptic plasticity without promoting toxicity (Danbolt, 2001).

Following this line of reasoning, we could hypothesize that after exposure to highest levels of ACE G/G homozygotes are more vulnerable to stress and report the highest damage to brain volume as a consequence
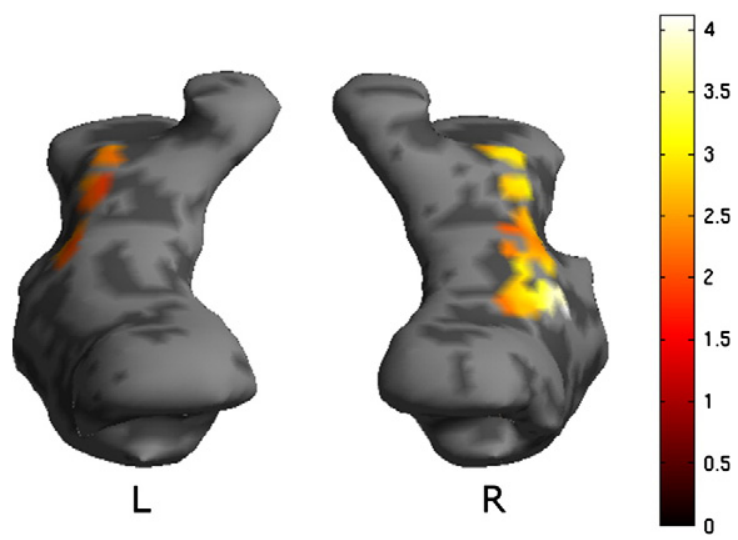

Fig. 1. 3D reconstruction of bilateral hippocampi with parahippocampal gyri in MNI space with overlaid areas where a significant effect of both ACE and SLA1A2-181A $>$ C was observed at a statistical threshold of $\mathrm{p}<0.05$ FWE corrected. of an excess of free glutamate (Kim et al., 2011). This effect could not be specific to ACE but extend to other kind of insults such as stroke, which caused the highest damage in G/G (Mallolas et al., 2006).

A gray matter volume reduction in hippocampus, in subjects reporting higher levels of ACE, is consistent with literature on both animals (Andersen and Teicher, 2004) and healthy humans (Teicher et al., 2012). Early life events have been shown to set in motion a series of adverse mechanisms that lead to the progressive loss of hippocampal synapses rather than an immediate loss of density (Andersen and Teicher, 2004). Hence the deleterious effect of ACE will become evident only in adulthood. Studies in animal models suggest that volume reduction in the hippocampus after chronic stress could be a consequence of a retraction of dendrites and spine density reduction and that this occurrence could be due either to the excitotoxic effect of an excess of glutamate, or to adaptive protective strategies to reduce the excitatory input in the face of increased glutamate release (Gorman and Docherty, 2010; McEwen, 2010). Our present observations extend the relationship between early stress and reduced hippocampal volume to patients with $\mathrm{BD}$ exposed to harsh parenting.

Understanding the mechanism underlying the disruption of hippocampal function and structure and how genetic and environmental factors interact in this region is particularly important due to the role of hippocampus not only in cognitive, learning and memory functions (Bliss and Collingridge, 1993; Segal, 2005) but also in the inhibition of stress responses (McEwen and Magarinos, 2001), in the regulation of affective states and emotional behavior (Phillips et al., 2003a) and in providing contextual information in conditioning and extinction (SotresBayon et al., 2006). Impaired appraisal of emotional stimuli and inability to control emotional response (Phillips et al., 2003b) have been suggested to be related to the core symptoms experienced by individuals

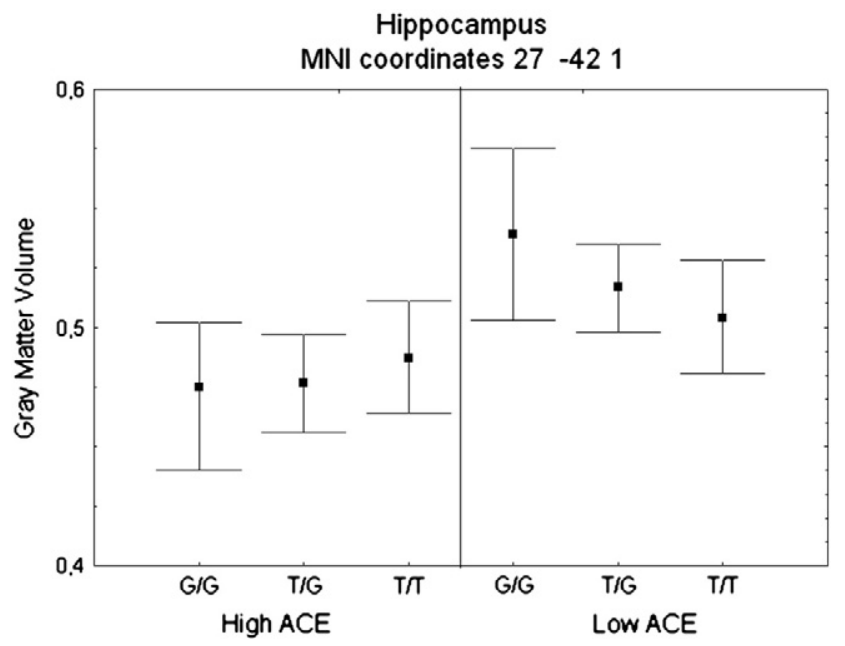

Fig. 2. Conjunction analysis between ACE and SLA1A2-181A > C Direction and size effects of the observed differences. Points are estimated regression coefficients, whiskers are standard errors. 


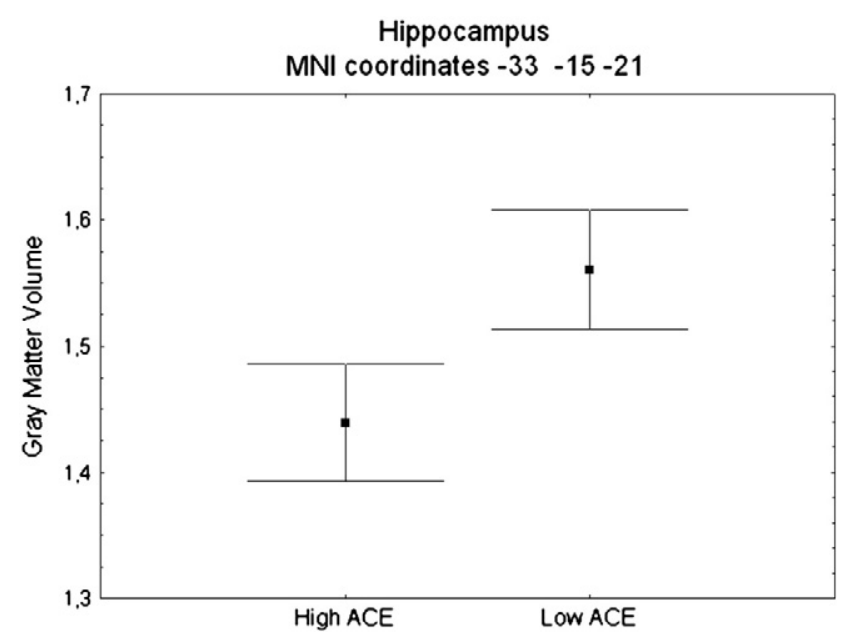

Fig. 3. Main effect of ACE. Direction and size effects of the observed differences. Points are estimated regression coefficients, whiskers are standard errors.

with $\mathrm{BD}$ (extreme depression/euphoria, mood liability, irritability, and distractibility). The effect of ACE on the hippocampus could contribute to this emotional instability.

The major limitation of the study is the lack of information regarding previous psychopharmacological treatments, received by the patients. Recent studies showed that highly complex medication regimens are often required during naturalistic outpatient treatment of BD depression (Post et al., 2010). Further prospective studies will consider drug treatments and other factors (e.g. other genes, drugs, exposure to emotional and physical stressors) to assess the potential role of SLA1A2-181A > C in bipolar illness. Also as suggested by Cousins et al. (2013) automated techniques like VBM could lead to potential artifact especially when lithium is involved.

Finally, limitations also include issues such as generalizability, possible undetected past comorbidities, population stratification and absence of placebo control. Moreover genome-wide association studies and gene-gene and gene-environment interactions were not taken into account.

\section{Conclusions}

A sparse but consistent literature associated BD and its most detrimental clinical features with a reduced glutamate import to brain structures. In our study we demonstrated an association between glutamate transporter polymorphism and early stress in influencing hippocampal gray matter volume in these patients. Higher ACE were associated with lower gray matter volume; moreover carriers of the rs $4354668 \mathrm{G}$ allele, which is associated with less transporter expression and a 30\% reduction in promoter activity compared with the T allele, had higher GM volumes than T/T homozygote when exposed to lower ACE. Carriers of the $G$ allele seem to be more vulnerable to stress: the exposure to a higher burden of ACE leads this group to a greater loss of brain volume, possibly due to an excess of free glutamate.

\section{Acknowledgments}

None.

\section{Role of funding source}

No sponsor for this study, except the authors themselves and their institution.

\section{Contributors}

SP designed the study. ES and FB obtained the funding. CC, CLoc and FB were involved in participants' recruitment and selection. SP, DR and CLoc performed MRI scanning. CLor and AP performed the genotyping. SP wrote the first draft of the manuscript, with other authors contributing to data interpretation and final manuscript preparation. All authors have approved the final article. FB and SP had full access to all of the data in the study and take responsibility for the integrity of the data and the accuracy of the data analysis.

\section{Conflict of interest}

The authors of this paper do not have any commercial association that might pose a conflict of interest in connection with this manuscript. None of the authors have financial disclosures pertinent to the contents of the manuscript. Our research unit received research grants from the Italian Ministry of University and Scientific Research, from the Italian Ministry of Health, and from the European Union (FP7 grant 222963).

\section{References}

Alloy LB, Abramson LY, Smith JM, Gibb BE, Neeren AM. Role of parenting and maltreatment histories in unipolar and bipolar mood disorders: mediation by cognitive vulnerability to depression. Clin Child Fam Psychol Rev 2006;9:23-64.

American Psychiatric Association. Diagnostic and statistical manual of mental disorders 4th ed. Washington, DC: American Psychiatric Association; 1994.

Andersen SL, Teicher MH. Delayed effects of early stress on hippocampal development Neuropsychopharmacology 2004;29:1988-93.

Andersen SL, Tomada A, Vincow ES, Valente E, Polcari A, Teicher MH. Preliminary evidence for sensitive periods in the effect of childhood sexual abuse on regional brain development. J Neuropsychiatry Clin Neurosci 2008;20:292-301.

Ashburner J, Friston KJ. Unified segmentation. Neuroimage 2005;26:839-51.

Atmaca M, Yildirim H, Ozdemir H, Poyraz AK, Tezcan E, Ogur E. Hippocampal 1H MRS in first-episode bipolar I patients. Prog Neuropsychopharmacol Biol Psychiatry 2006;30: 1235-9.

Autry AE, Grillo CA, Piroli GG, Rothstein JD, McEwen BS, Reagan LP. Glucocorticoid regulation of GLT-1 glutamate transporter isoform expression in the rat hippocampus. Neuroendocrinology 2006;83:371-9.

Bauer D, Haroutunian V, Meador-Woodruff JH, McCullumsmith RE. Abnormal glycosylation of EAAT1 and EAAT2 in prefrontal cortex of elderly patients with schizophrenia. Schizophr Res 2010;117:92-8.

Benedetti F, Calabrese G, Bernasconi A, Cadioli M, Colombo C, Dallaspezia S, et al. Spectroscopic correlates of antidepressant response to sleep deprivation and light therapy: a 3.0 Tesla study of bipolar depression. Psychiatry Res 2009;173:238-42.

Benedetti F, Radaelli D, Poletti S, Falini A, Cavallaro R, Dallaspezia S, et al. Emotional reactivity in chronic schizophrenia: structural and functional brain correlates and the influence of adverse childhood experiences. Psychol Med 2011;41:509-19.

Benedetti F, Poletti S, Radaelli D, Pozzi E, Giacosa C, Ruffini C, et al. Caudate gray matter volume in obsessive-compulsive disorder is influenced by adverse childhood experiences and ongoing drug treatment. J Clin Psychopharmacol 2012;32:544-7.

Bearden CE, Thompson PM, Dutton RA, Frey BN, Peluso MA, Nicoletti M, et al. Three-dimensional mapping of hippocampal anatomy in unmedicated and lithium-treated patients with bipolar disorder. Neuropsychopharmacol 2008;33: 1229-38.

Bertolino A, Frye M, Callicott JH, Mattay VS, Rakow R, Shelton-Repella J, et al. Neuronal pathology in the hippocampal area of patients with bipolar disorder: a study with proton magnetic resonance spectroscopic imaging. Biol Psychiatry 2003;53:906-13.

Blasi G, Bertolino A, Brudaglio F, Sciota D, Altamura M, Antonucci N, et al. Hippocampal neurochemical pathology in patients at first episode of affective psychosis: a proton magnetic resonance spectroscopic imaging study. Psychiatry Res 2004;131:95-105.

Bliss TV, Collingridge GL. A synaptic model of memory: long-term potentiation in the hippocampus. Nature 1993;361:31-9.

Bremner JD, Randall P, Vermetten E, Staib L, Bronen RA, Mazure C, et al. Magnetic resonance imaging-based measurement of hippocampal volume in posttraumatic stress disorder related to childhood physical and sexual abuse - a preliminary report. Biol Psychiatry 1997;41:23-32.

Brodsky BS, Oquendo M, Ellis SP, Haas GL, Malone KM, Mann JJ. The relationship of childhood abuse to impulsivity and suicidal behavior in adults with major depression. Am J Psychiatry 2001;158:1871-7.

Castillo M, Kwock L, Courvoisie H, Hooper SR. Proton MR spectroscopy in children with bipolar affective disorder: preliminary observations. AJNR Am J Neuroradiol 2000;21:832-8.

Cecil KM, DelBello MP, Morey R, Strakowski SM. Frontal lobe differences in bipolar disorder as determined by proton MR spectroscopy. Bipolar Disord 2002;4:357-65.

Clark JF, Doepke A, Filosa JA, Wardle RL, Lu A, Meeker TJ, et al. N-acetylaspartate as a reservoir for glutamate. Med Hypotheses 2006;67:506-12.

Colla M, Schubert F, Bubner M, Heidenreich JO, Bajbouj M, Seifert F, et al. Glutamate as a spectroscopic marker of hippocampal structural plasticity is elevated in long-term 
euthymic bipolar patients on chronic lithium therapy and correlates inversely with diurnal cortisol. Mol Psychiatry 2009;14:696-704. [647].

Cousins DA, Aribisala B, Nicol Ferrier I, Blamire AM. Lithium, gray matter, and magnetic resonance imaging signal. Biol Psychiatry 2013;73:652-7.

Dager SR, Friedman SD, Parow A, Demopulos C, Stoll AL, Lyoo IK, et al. Brain metabolic alterations in medication-free patients with bipolar disorder. Arch Gen Psychiatry 2004;61:450-8.

Danbolt NC. Glutamate uptake. Prog Neurobiol 2001;65:1-105.

Duan S, Anderson CM, Stein BA, Swanson RA. Glutamate induces rapid upregulation of astrocyte glutamate transport and cell-surface expression of GLAST. J Neurosci 1999;19:10193-200.

Felitti VJ, Anda RF, Nordenberg D, Williamson DF, Spitz AM, Edwards V, et al. Relationship of childhood abuse and household dysfunction to many of the leading causes of death in adults. The Adverse Childhood Experiences (ACE) Study. Am J Prev Med 1998;14: 245-58.

First MB, Spitzer RL, Gibbon M, Williams JBW. Structured clinical interview for DSM-IV Axis I disorders, clinician version (SCID-CV). Washington, D.C.: American Psychiatric Press, Inc.; 1996

Fontella FU, Vendite DA, Tabajara AS, Porciuncula LO, da Silva Torres IL, Jardim FM, et al. Repeated restraint stress alters hippocampal glutamate uptake and release in the rat. Neurochem Res 2004;29:1703-9.

Frodl T, Reinhold E, Koutsouleris N, Reiser M, Meisenzahl EM. Interaction of childhood stress with hippocampus and prefrontal cortex volume reduction in major depression. J Psychiatr Res 2010;44:799-807.

Geoffroy PA, Etain B, Houenou J. Gene $\times$ environment interactions in schizophrenia and bipolar disorder: evidence from neuroimaging. Front Psychiatry 2013;4: 136.

Geuze E, Vermetten E, Bremner JD. MR-based in vivo hippocampal volumetrics: 2. Findings in neuropsychiatric disorders. Mol Psychiatry 2005;10:160-84.

Gilad GM, Gilad VH, Wyatt RJ, Tizabi Y. Region-selective stress-induced increase of glutamate uptake and release in rat forebrain. Brain Res 1990;525:335-8.

Gladstone G, Parker G, Wilhelm K, Mitchell P, Austin MP. Characteristics of depressed patients who report childhood sexual abuse. Am J Psychiatry 1999;156:431-7.

Good CD, Johnsrude IS, Ashburner J, Henson RN, Friston KJ, Frackowiak RS. A voxel-based morphometric study of ageing in 465 normal adult human brains. Neuroimage 2001;14:21-36.

Gorman JM, Docherty JP. A hypothesized role for dendritic remodeling in the etiology of mood and anxiety disorders. J Neuropsychiatry Clin Neurosci 2010;22: 256-64.

Hajek T, Kopecek M, Preiss M, Alda M, Hoschl C. Prospective study of hippocampal volume and function in human subjects treated with corticosteroids. Eur Psychiatry 2006;21:123-8.

Hashimoto K, Sawa A, Iyo M. Increased levels of glutamate in brains from patients with mood disorders. Biol Psychiatry 2007;62:1310-6.

Hulshoff Pol HE, van Baal GC, Schnack HG, Brans RG, van der Schot AC, Brouwer RM, et al. Overlapping and segregating structural brain abnormalities in twins with schizophrenia or bipolar disorder. Arch Gen Psychiatry 2012;69:349-59.

Joels M. Corticosteroid effects in the brain: U-shape it. Trends Pharmacol Sci 2006;27: 244-50.

Johnson SL, Roberts JE. Life events and bipolar disorder: implications from biological theories. Psychol Bull 1995;117:434-49.

Kalkman HO. Circumstantial evidence for a role of glutamine-synthetase in suicide. Med Hypotheses 2011;76:905-7.

Kim K, Lee SG, Kegelman TP, Su ZZ, Das SK, Dash R, et al. Role of excitatory amino acid transporter-2 (EAAT2) and glutamate in neurodegeneration: opportunities for developing novel therapeutics. J Cell Physiol 2011;126:2484-93.

Klempan TA, Sequeira A, Canetti L, Lalovic A, Ernst C, ffrench-Mullen J, Turecki G. Altered expression of genes involved in ATP biosynthesis and GABAergic neurotransmission in the ventral prefrontal cortex of suicides with and without major depression. Mol Psychiatry 2009;14:175-89.

Krystal JH, Sanacora G, Blumberg H, Anand A, Charney DS, Marek G, et al. Glutamate and GABA systems as targets for novel antidepressant and mood-stabilizing treatments. Mol Psychiatry 2002;7(Suppl. 1):S71-80.

Liang J, Takeuchi H, Doi Y, Kawanokuchi J, Sonobe Y, Jin S, et al. Excitatory amino acid transporter expression by astrocytes is neuroprotective against microglial excitotoxicity. Brain Res 2008;1210:11-9.

Luborzewski A, Schubert F, Seifert F, Danker-Hopfe H, Brakemeier EL, Schlattmann P, et al. Metabolic alterations in the dorsolateral prefrontal cortex after treatment with high-frequency repetitive transcranial magnetic stimulation in patients with unipolar major depression. J Psychiatr Res 2007;41:606-15.

Machado-Vieira R, Salvadore G, Diazgranados N, Zarate Jr CA. Ketamine and the next generation of antidepressants with a rapid onset of action. Pharmacol Ther 2009;123: $143-50$

Mallolas J, Hurtado O, Castellanos M, Blanco M, Sobrino T, Serena J, et al. A polymorphism in the EAAT2 promoter is associated with higher glutamate concentrations and higher frequency of progressing stroke. J Exp Med 2006;203:711-7.

Manji HK, Quiroz JA, Payne JL, Singh J, Lopes BP, Viegas JS, et al. The underlying neurobiology of bipolar disorder. World Psychiatry 2003;2:136-46.

Marcus SR, Nadiger HA, Chandrakala MV, Rao TI, Sadasivudu B. Acute and short-term effects of lithium on glutamate metabolism in rat brain. Biochem Pharmacol 1986;35:365-9.

McEwen BS. Stress and hippocampal plasticity. Annu Rev Neurosci 1999;22:105-22.

McEwen BS. Physiology and neurobiology of stress and adaptation: central role of the brain. Physiol Rev 2007;87:873-904.

McEwen BS. Stress, sex, and neural adaptation to a changing environment: mechanisms of neuronal remodeling. Ann N Y Acad Sci 2010;1204:E38-59. [Suppl.]
McEwen BS, Magarinos AM. Stress and hippocampal plasticity: implications for the pathophysiology of affective disorders. Hum Psychopharmacol 2001;16:S7-S19.

McKinnon MC, Yucel K, Nazarov A, MacQueen GM. A meta-analysis examining clinical predictors of hippocampal volume in patients with major depressive disorder. J Psychiatry Neurosci 2009;34:41-54.

Medina A, Burke S, Thompson RC, Bunney Jr W, Myers RM, Schatzberg A, et al. Glutamate transporters: a key piece in the glutamate puzzle of major depressive disorder. J Psychiatr Res 2013:47:1150-6.

Meyer T, Ludolph AC, Morkel M, Hagemeier C, Speer A. Genomic organization of the human excitatory amino acid transporter gene GLT-1. Neuroreport 1997;8:775-7.

Moghaddam B, Adams B, Verma A, Daly D. Activation of glutamatergic neurotransmission by ketamine: a novel step in the pathway from NMDA receptor blockade to dopaminergic and cognitive disruptions associated with the prefrontal cortex. J Neurosci 1997; $17: 2921-7$.

Moore GJ, Bebchuk JM, Hasanat K, Chen G, Seraji-Bozorgzad N, Wilds IB, et al. Lithium increases $\mathrm{N}$-acetyl-aspartate in the human brain: in vivo evidence in support of bcl-2's neurotrophic effects? Biol Psychiatry 2000;48:1-8.

Moorhead TW, McKirdy J, Sussmann JE, Hall J, Lawrie SM, Johnstone EC, et al. Progressive gray matter loss in patients with bipolar disorder. Biol Psychiatry 2007;62: 894-900

Newport DJ, Stowe ZN, Nemeroff CB. Parental depression: animal models of an adverse life event. Am J Psychiatry 2002;159:1265-83.

Ohnuma T, Augood SJ, Arai H, McKenna PJ, Emson PC. Expression of the human excitatory amino acid transporter 2 and metabotropic glutamate receptors 3 and 5 in the prefrontal cortex from normal individuals and patients with schizophrenia. Brain Res Mol Brain Res 1998:56:207-17.

Ohnuma T, Tessler S, Arai H, Faull RL, McKenna PJ, Emson PC. Gene expression of metabotropic glutamate receptor 5 and excitatory amino acid transporter 2 in the schizophrenic hippocampus. Brain Res Mol Brain Res 2000;85:24-31.

Oldfield RC. The assessment and analysis of handedness: the Edinburgh inventory. Neuropsychologia 1971;9:97-113.

Phillips ML, Drevets WC, Rauch SL, Lane R. Neurobiology of emotion perception I: the neural basis of normal emotion perception. Biol Psychiatry 2003a;54: 504-14

Phillips ML, Drevets WC, Rauch SL, Lane R. Neurobiology of emotion perception II: implications for major psychiatric disorders. Biol Psychiatry 2003b;54:515-28.

Popoli M, Yan Z, McEwen BS, Sanacora G. The stressed synapse: the impact of stress and glucocorticoids on glutamate transmission. Nat Rev Neurosci 2012;13:22-37.

Post RM, Leverich GS, Xing G, Weiss RB. Developmental vulnerabilities to the onset and course of bipolar disorder. Dev Psychopathol 2001;13:581-98.

Post RM, Altshuler LL, Frye MA, Suppes T, Keck Jr PE, McElroy SL, et al. Complexity of pharmacologic treatment required for sustained improvement in outpatients with bipolar disorder. J Clin Psychiatry 2010;71:1176-86. [quiz 1252-1173].

Rao JS, Kellom M, Reese EA, Rapoport SI, Kim HW. Dysregulated glutamate and dopamine transporters in postmortem frontal cortex from bipolar and schizophrenic patients. J Affect Disord 2012;136:63-71.

Rauen T, Wiessner M. Fine tuning of glutamate uptake and degradation in glial cells: common transcriptional regulation of GLAST1 and GS. Neurochem Int 2000;37: 179-89.

Reagan LP, Rosell DR, Wood GE, Spedding M, Munoz C, Rothstein J, et al. Chronic restraint stress up-regulates GLT-1 mRNA and protein expression in the rat hippocampus: reversal by tianeptine. Proc Natl Acad Sci U S A 2004;101:2179-84.

Rosenberg PA, Aizenman E. Hundred-fold increase in neuronal vulnerability to glutamate toxicity in astrocyte-poor cultures of rat cerebral cortex. Neurosci Lett 1989;103: $162-8$.

Rothstein JD, Dykes-Hoberg M, Pardo CA, Bristol LA, Jin L, Kuncl RW, et al. Knockout of glutamate transporters reveals a major role for astroglial transport in excitotoxicity and clearance of glutamate. Neuron 1996;16:675-86.

Segal M. Dendritic spines and long-term plasticity. Nat Rev Neurosci 2005;6:277-84.

Singh J, Zarate Jr CA, Krystal AD. Case report: successful riluzole augmentation therapy in treatment-resistant bipolar depression following the development of rash with lamotrigine. Psychopharmacology (Berl) 2004;173:227-8.

Smith RE, Haroutunian V, Davis KL, Meador-Woodruff JH. Expression of excitatory amino acid transporter transcripts in the thalamus of subjects with schizophrenia. Am J Psychiatry 2001;158:1393-9.

Sotres-Bayon F, Cain CK, LeDoux JE. Brain mechanisms of fear extinction: historical perspectives on the contribution of prefrontal cortex. Biol Psychiatry 2006;60: 329-36.

Swann AC, Dougherty DM, Pazzaglia PJ, Pham M, Steinberg JL, Moeller FG. Increased impulsivity associated with severity of suicide attempt history in patients with bipolar disorder. Am J Psychiatry 2005;162:1680-7.

Taylor SE, Lerner JS, Sage RM, Lehman BJ, Seeman TE. Early environment, emotions, responses to stress, and health. J Pers 2004;72:1365-93.

Taylor SE, Eisenberger NI, Saxbe D, Lehman BJ, Lieberman MD. Neural responses to emotional stimuli are associated with childhood family stress. Biol Psychiatry 2006;60: 296-301.

Teicher MH, Anderson CM, Polcari A. Childhood maltreatment is associated with reduced volume in the hippocampal subfields CA3, dentate gyrus, and subiculum. Proc Natl Acad Sci U S A 2012:109:E563-72.

Weller ML, Stone IM, Goss A, Rau T, Rova C, Poulsen DJ. Selective overexpression of excitatory amino acid transporter 2 (EAAT2) in astrocytes enhances neuroprotection from moderate but not severe hypoxia-ischemia. Neuroscience 2008; $155: 1204-11$

Weniger G, Lange C, Sachsse U, Irle E. Reduced amygdala and hippocampus size in trauma-exposed women with borderline personality disorder and without posttraumatic stress disorder. J Psychiatry Neurosci 2009;34:383-8. 
Wermter AK, Laucht M, Schimmelmann BG, Banaschweski T, Sonuga-Barke EJ, Rietschel $\mathrm{M}$, et al. From nature versus nurture, via nature and nurture, to gene $\times$ environment interaction in mental disorders. Eur Child Adolesc Psychiatry 2010;19:199-210.

Yang $\mathrm{CH}$, Huang CC, Hsu KS. Behavioral stress enhances hippocampal CA1 long-term depression through the blockade of the glutamate uptake. J Neurosci 2005;25: 4288-93.
Yucel K, Taylor VH, McKinnon MC, Macdonald K, Alda M, Young LT, et al. Bilateral hippocampal volume increase in patients with bipolar disorder and short-term lithium treatment. Neuropsychopharmacology 2008;33:361-7.

Zarate Jr CA, Quiroz JA, Singh JB, Denicoff KD, De Jesus G, Luckenbaugh DA, et al. An open-label trial of the glutamate-modulating agent riluzole in combination with lithium for the treatment of bipolar depression. Biol Psychiatry 2005;57:430-2. 